\title{
Microstructure and magnetic properties of FeCoN thin films
}

\author{
P. C. Kuo, S. S. Chang, and C. M. Kuo \\ Institute of Materials Science and Engineering, National Taiwan University, Taipei, Taiwan \\ Y. D. Yao \\ Institute of Physics, Academia Sinica, Taipei 115, Taiwan \\ H. L. Huang \\ Department of Physics, National Taiwan University, Taipei, Taiwan
}

Effects of nitrogen contents and substrate temperatures to the microstructure and magnetic properties of the FeCoN films have been investigated. According to the TEM and X-ray Scherrer's equation analyses, we found that the grain size of films with substrate temperature below $200{ }^{\circ} \mathrm{C}$ is roughly about $13 \mathrm{~nm}$, however, it increases very fast for films with substrate temperature above $300{ }^{\circ} \mathrm{C}$. $\mathrm{N}$ content in the films is saturated to 30 at. \%, as $\mathrm{N}_{2}$ flow ratio $\mathrm{N}_{2} /\left(\mathrm{Ar}+\mathrm{N}_{2}\right)$ is higher than 5 vol. $\%$. From the magnetization studies, we have found that the saturation magnetization $4 \pi M_{s}$ of the optimum samples (with the substrate temperature near $200{ }^{\circ} \mathrm{C}$ ) is $23.9 \mathrm{kG}$. The improvement of the magnetic properties is attributed to the combination of $\alpha$-Fe with $\mathrm{N}$ to form the high magnetic moment FeN phases. (C) 1998 American Institute of Physics. [S0021-8979(98)35011-2]

\section{INTRODUCTION}

A soft magnetic film with high saturation magnetization $4 \pi M_{s}$ is required for use in a high-density magnetic recording head. Recently, extensive efforts have been made to improve the soft magnetic properties of Fe-based films. ${ }^{1-7}$ According to the Pauling-Slater curve, $\mathrm{Fe}-\mathrm{Co}$ alloys have the highest magnetization of iron alloy. Takahashi et al. ${ }^{8}$ prepared FeCo nitride film onto a polyimide substrate by ionassisted normally vapor deposition method. They found that the film was columnar structure with large grains of about $500 \AA$ and maximum $4 \pi M_{s}$ occurred at the Co content of about 32 at. \%. Their films have large perpendicular magnetic anisotropy and $\mathrm{N}$ content of the film is unknown. On the other hand, $\mathrm{Liao}^{9}$ reported that electrodeposited $\mathrm{Fe}_{90} \mathrm{Co}_{10}$ films show a high $4 \pi M_{s}$ value of $19 \mathrm{kG}$ and good soft magnetic properties. Recently, Nakagawa et al. ${ }^{10}$ examined the FeCoN and FeCoTaN films which prepared by facing targets sputtering with $\mathrm{N}_{2}+\mathrm{Kr}$ mixture gas. They found that $4 \pi M_{s}$ of the film was decreased with increasing $\mathrm{N}_{2}$ partial pressure. Pure $\mathrm{Fe}_{90} \mathrm{Co}_{10}$ alloy film has an extremely large $4 \pi M_{s}$ of about $24 \mathrm{kG}$. In this report, we investigate the effect of substrate temperature and $\mathrm{N}$ content on the magnetic properties and microstructures of sputtered FeCoN films.

\section{EXPERIMENT}

$\left(\mathrm{Fe}_{0.9} \mathrm{Co}_{0.1}\right)_{100-x} \mathrm{~N}_{x}$ films with $x=0-30$ were prepared on a precleaned glass substrate by reactive $\mathrm{RF}$ magnetron sputtering in $\mathrm{N}_{2}$ and Ar mixed atmosphere. The flow ratio of nitrogen to argon and nitrogen, i.e., $\mathrm{N}_{2} /\left(\mathrm{Ar}+\mathrm{N}_{2}\right)$, during sputtering was varied between 0 and 10 vol. $\%$. The substrate temperature was varied between 25 and $400{ }^{\circ} \mathrm{C}$. Composite target consisting of pure Fe disk overlaid with Co pieces was used in this experiment. The base pressure in the system with a turbo pump was $1 \times 10^{-6}$ Torr, and after the high purity $\mathrm{Ar}-\mathrm{N}_{2}$ mixed gas was introduced, sputtering pressure was $1 \times 10^{-3}$ Torr. Thickness of the films was about $200 \mathrm{~nm}$.

Structure and grain size of the films were determined by using x-ray diffractometer (XRD). Thickness of the films was measured by a Sloan DEKTAK-3-0305ST $\alpha$-step profilometer. Magnetic properties of the films were measured with vibrating sample magnetometer (VSM) at room temperature with maximum applied field of $12 \mathrm{kOe}$. Composition, $\mathrm{N}$ content, and homogeneity of the films were determined by depth profiling analysis of Auger electron spectroscopy (AES).

\section{RESULTS AND DISCUSSION}

Figure 1 shows the $\mathrm{N}$ contents in pure $\mathrm{Fe}, \mathrm{Co}$, and $\mathrm{Fe}_{90} \mathrm{Co}_{10}$ films as a function of $\mathrm{N}_{2}$ flow ratio during sputtering, i.e., $\left(\mathrm{N}_{2} / \mathrm{Ar}+\mathrm{N}_{2}\right) \times 100 \%$, with the substrate temperature $T_{s}$ kept at $25^{\circ} \mathrm{C}$. It can be seen that $\mathrm{N}$ content in the films increases dramatically with increasing $\mathrm{N}_{2}$ flow ratio when $\mathrm{N}_{2}$ flow ratio is lower than 5 vol. \%. This is because $\mathrm{N}$ atoms can easily occupy interstitial sites of crystal lattice during deposition as $\mathrm{N}_{2}$ flow ratio is lower than 5 vol. \%. $\mathrm{N}$ content in the film is saturated as $\mathrm{N}_{2}$ flow ratio is higher than 5 vol. \% for all films. This is due to that all interstitial sites of crystal lattices in the film are occupied. Saturated N content of $\mathrm{Fe}$ film is about 32 at. \% which is equal to the $\mathrm{N}$ content of $\zeta-\mathrm{Fe}_{2} \mathrm{~N}$ phase. ${ }^{11} \zeta-\mathrm{Fe}_{2} \mathrm{~N}$ phase is nonmagnetic and has maximum equilibrium $\mathrm{N}$ content in $\mathrm{Fe}-\mathrm{N}$ binary system. ${ }^{12}$ The maximum $\mathrm{N}$ contents of $\mathrm{Fe}_{90} \mathrm{Co}_{10}$ and $\mathrm{Co}$ films are 30 and 23 at. \%, respectively. Figure 2 presents a 


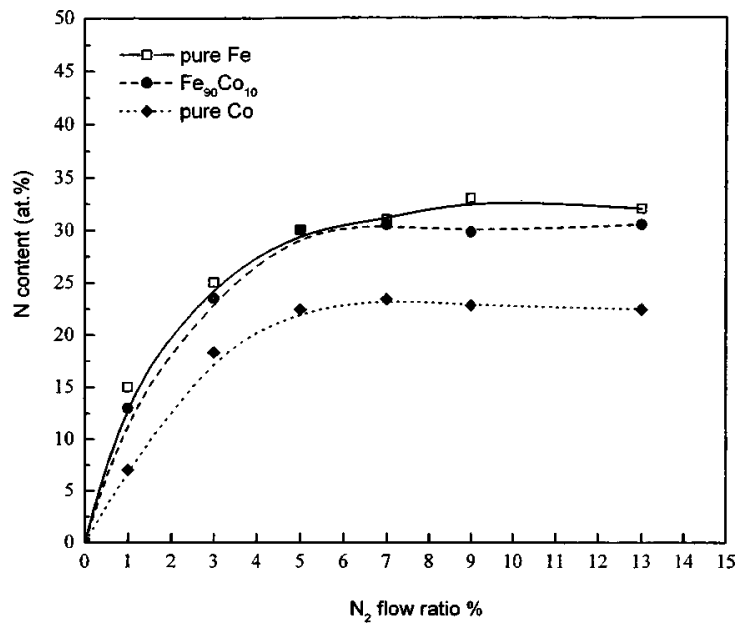

FIG. 1. Variation of $\mathrm{N}$ content with $\mathrm{N}_{2}$ flow ratio of $\mathrm{Fe}, \mathrm{Fe}_{90} \mathrm{Co}_{10}$ and $\mathrm{Co}$ films. The substrate temperature is kept at $25^{\circ} \mathrm{C}$.

typical depth profile of a $\mathrm{FeCoN}$ film analyzed by Auger electron spectroscopy (AES). We can see that the composition of this film is approximately $\left(\mathrm{Fe}_{0.9} \mathrm{Co}_{0.1}\right)_{70} \mathrm{~N}_{30}$. It is calibrated by a standard of bulk $\mathrm{Fe}_{50} \mathrm{Co}_{50}$ alloy. Because the films were exposed to air prior to AES analysis, near the surface of the films, $\mathrm{O}$ and $\mathrm{C}$ were always observed as shown in Fig. 2.

Typical microstructure of the $\left(\mathrm{Fe}_{0.9} \mathrm{Co}_{0.1}\right)_{100-x} \mathrm{~N}_{x}$ films is shown in Fig. 3. Figure 3(a) is a TEM photograph of the $\left(\mathrm{Fe}_{0.9} \mathrm{Co}_{0.1}\right)_{77} \mathrm{~N}_{23}$ film with substrate temperature of $25^{\circ} \mathrm{C}$. We can see that the film has a nanocrystalline structure and its average grain size is about $13 \mathrm{~nm}$. In Fig. 3(b), from the diffraction lines of the electron diffraction pattern of this film, we noticed that $\epsilon-\mathrm{Fe}_{2-3} \mathrm{~N}, \mathrm{Co}_{2} \mathrm{~N}, \gamma^{\prime}-\mathrm{Fe}_{4} \mathrm{~N}$, and $\zeta-\mathrm{Fe}_{2} \mathrm{~N}$ phases are included.

Figure 4 shows the saturation magnetization $4 \pi M_{s}$ and coercivity $H_{c}$ as a function of $\mathrm{N}$ content in $\left(\mathrm{Fe}_{0.9} \mathrm{Co}_{0.1}\right)_{100-x} \mathrm{~N}_{x}$ films with its substrate temperature at $25^{\circ} \mathrm{C}$. It is clear that $4 \pi M_{s}$, and both in-plane coercivity $H_{c \|}$ and perpendicular coercivity $H_{c \perp}$ of the films increase slowly from 22 to $22.8 \mathrm{kG}, 12$ to $18 \mathrm{Oe}$, and 22 to $30 \mathrm{Oe}$, respectively, for $\mathrm{N}$ less than roughly 13 at. \%. However,

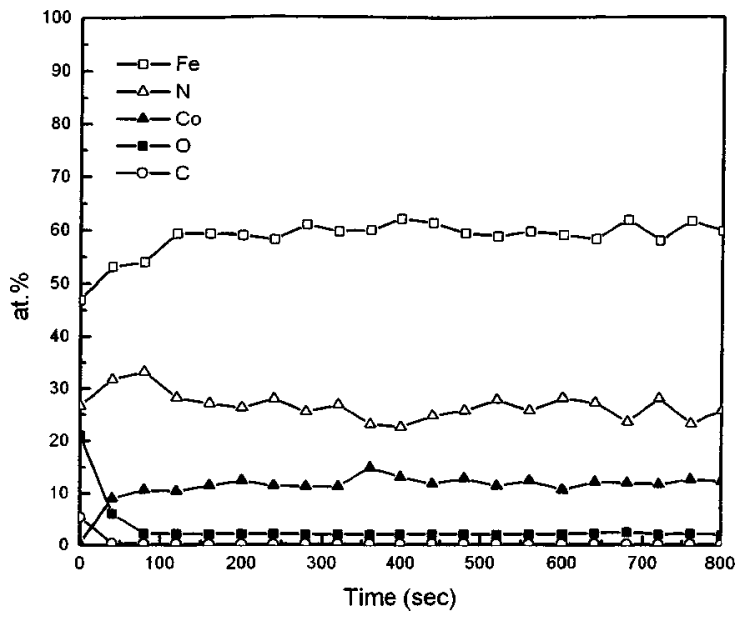

FIG. 2. Auger depth profile of a $\left(\mathrm{Fe}_{0.9} \mathrm{Co}_{0.1}\right)_{70} \mathrm{~N}_{30}$ film.
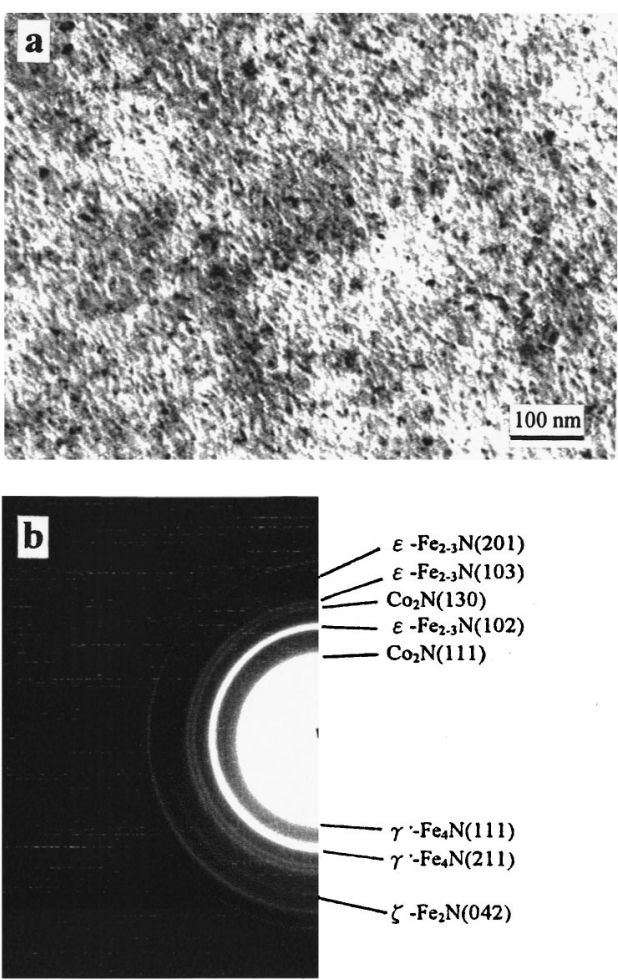

FIG. 3. TEM micrograph and electron diffraction pattern of $\left(\mathrm{Fe}_{0.9} \mathrm{Co}_{0.1}\right)_{77} \mathrm{~N}_{23}$ film with $T_{s}=25^{\circ} \mathrm{C}$. (a) is the microstructure of planar section and (b) is the corresponding electron diffraction pattern.

$4 \pi M_{s}$ decreases and both $H_{c}$ 's increase rapidly as $\mathrm{N}$ content is larger than 13 at. \%. When $\mathrm{N}$ content is approached to 30 at. \%, both $H_{c}$ increase to about 150 Oe and $4 \pi M_{s}$ decreases to about $2 \mathrm{kG}$ due to the formation of $\zeta-\mathrm{Fe}_{2} \mathrm{~N}$ phase in the film. The perpendicular coercivity $H_{c \perp}$ is slightly higher than that of the in-plane coercivity $H_{c \|}$. This indicates that the film is almost magnetic isotropy as substrate temperature is kept at $25^{\circ} \mathrm{C}$.

Figure 5 shows the relation between $4 \pi M_{s}, H_{c \|}, H_{c \perp}$ and substrate temperature $T_{s}$ of the $\left(\mathrm{Fe}_{0.9} \mathrm{Co}_{0.1}\right)_{100-x} \mathrm{~N}_{x}$ films prepared with the flow ratio of $\mathrm{N}_{2}$ at 1 vol. \% during sputtering. According to the AES analysis, the $\mathrm{N}$ content of the

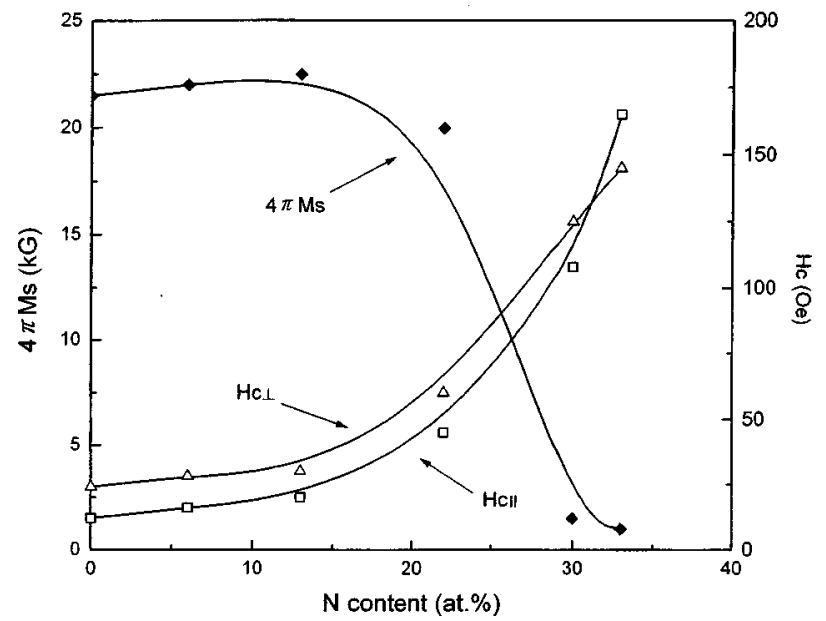

FIG. 4. Effect of $\mathrm{N}$ content on the $4 \pi M_{s}, H_{c \|}$, and $H_{c \perp}$ of $\left(\mathrm{Fe}_{0.9} \mathrm{Co}_{0.1}\right)_{100-x} \mathrm{~N}_{x}$ films. The substrate temperature is kept at $25^{\circ} \mathrm{C}$. 


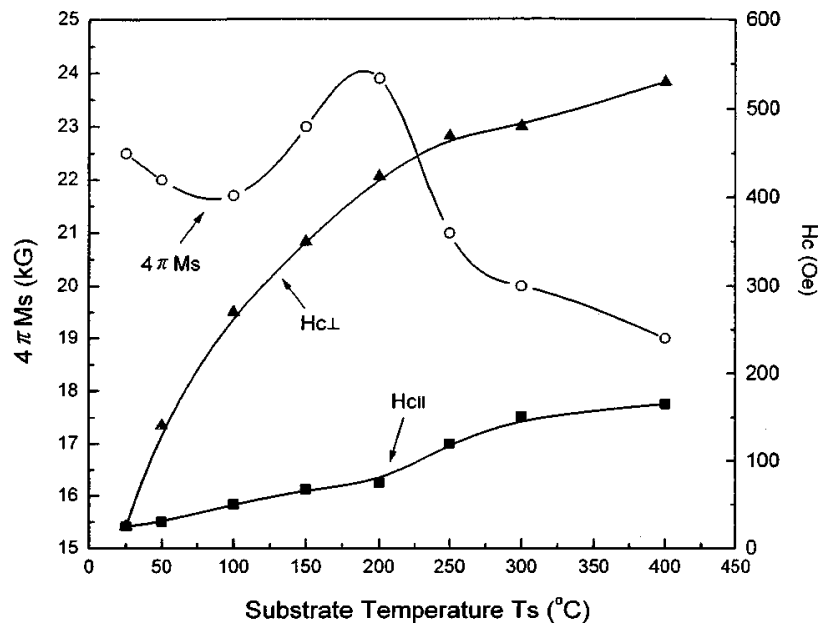

FIG. 5. The change of $4 \pi M_{s}, H_{c \|}$, and $H_{c \perp}$ against $T_{s}$ for $\left(\mathrm{Fe}_{0.9} \mathrm{Co}_{0.1}\right)_{100-x} \mathrm{~N}_{x}$ films. $\mathrm{N}_{2}$ flow ratio is 1 vol. \% during sputtering.

film was found to decrease from 13 at. $\%$ for $T_{s}=25^{\circ} \mathrm{C}$ to 10 at. $\%$ for $T_{s}=100{ }^{\circ} \mathrm{C}, 8$ at. $\%$ for $T_{s}=200{ }^{\circ} \mathrm{C}$, and 3 at. $\%$ for $T_{s}=400{ }^{\circ} \mathrm{C}$. It can be seen that $H_{c \|}$ increases monotonously from 25 to 165 Oe when $T_{s}$ increasing from 25 to $400{ }^{\circ} \mathrm{C}$, but $H_{c \perp}$ of the film is increased rapidly from 25 to 530 Oe. It is obvious that magnetic easy axis is in the film plane, as $T_{s}$ is higher than $25^{\circ} \mathrm{C}$. The increasing of coercivities with $T_{s}$ is owing to that $\mathrm{N}$ content of the film is decreased with increasing $T_{s}$. From the x-ray diffraction patterns study of the films at various $T_{s}$, we found that the amount of high coercivity FeCo phase is increased with $T_{s}$. For example, Fig. 6 shows curves (a) to (c) with their substrate temperatures at 25,100 , and $200^{\circ} \mathrm{C}$, respectively. When $T_{s}$ is higher than $300{ }^{\circ} \mathrm{C}$, only the FeCo peak can be detected by $\mathrm{x}$-ray diffractometer. According to the $\mathrm{x}$-ray Scherrer's equation analysis from the diffraction peak of $\mathrm{FeCo}(100)$, we found that the grain size of the films with substrate temperature below $200{ }^{\circ} \mathrm{C}$ is roughly about $13 \mathrm{~nm}$, however, it increases very fast for films with substrate temperature above $300^{\circ} \mathrm{C}$.

The $4 \pi M_{s}$ in Fig. 5 shows a minimum value of $21.7 \mathrm{kG}$ around $100{ }^{\circ} \mathrm{C}$, and a maximum value of $24 \mathrm{kG}$ at $T_{s}$ $\cong 200{ }^{\circ} \mathrm{C}$. Comparing with the $\mathrm{x}$-ray diffraction peaks of Figs. 6(a), 6(b), and 6(c), we can see that these films all contain high moment $\mathrm{FeCo}$ and $\alpha^{\prime}-\mathrm{Fe}_{6-10} \mathrm{~N}$ phases. ${ }^{13}$ From this point of view, variation of the $4 \pi M_{s}$ of film with $T_{s}$ is due to the change of $\mathrm{N}$ content in the film, i.e., amounts of various $\mathrm{FeN}, \mathrm{FeCo}, \mathrm{CoN}, \alpha$-Fe phases in the film are changed.

\section{CONCLUSIONS}

In conclusion, effects of nitrogen contents and substrate temperatures to the microstructure and magnetic properties of the $\left(\mathrm{Fe}_{0.9} \mathrm{Co}_{0.1}\right)_{100-x} \mathrm{~N}_{x}$ films with $x=0-30$ films have been investigated. TEM observation found that they have nanocrystalline structure. When $\mathrm{N}$ content of the film is

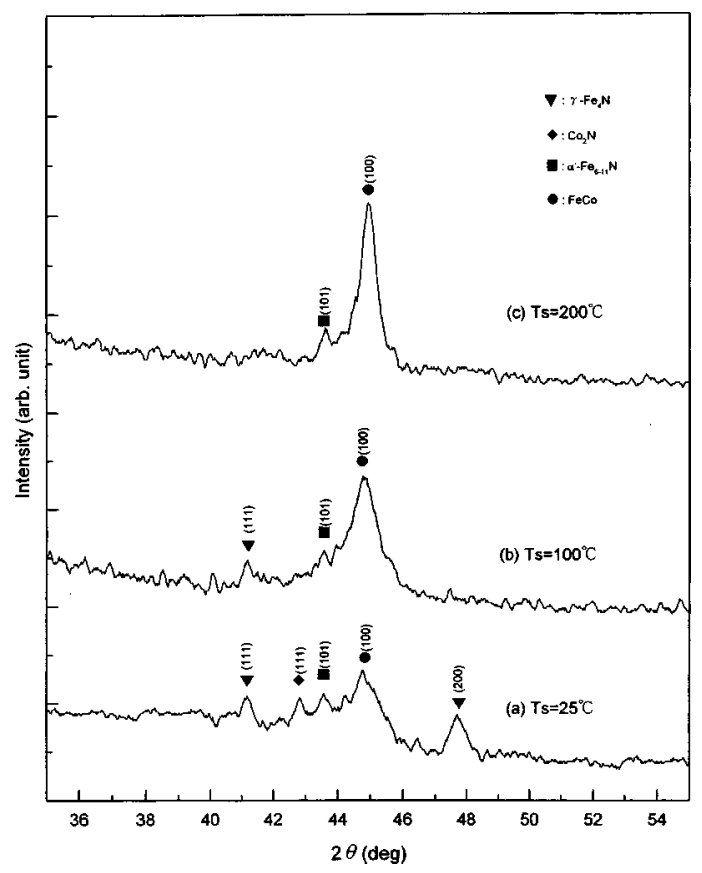

FIG. 6. X-ray diffraction patterns of various $\left(\mathrm{Fe}_{0.9} \mathrm{Co}_{0.1}\right)_{100-x} \mathrm{~N}_{x}$ films. $\mathrm{N}_{2}$ flow ratio is 1 vol. \% during sputtering and substrate temperatures are (a) $T_{s}=25^{\circ} \mathrm{C}$, (b) $T_{s}=100{ }^{\circ} \mathrm{C}$, and (c) $T_{s}=200{ }^{\circ} \mathrm{C}$.

lower than 13 at. \%, it contains high moment $\alpha^{\prime}-\mathrm{Fe}_{6-10} \mathrm{~N}, \quad \mathrm{FeCo}$, and $\gamma^{\prime}-\mathrm{Fe}_{4} \mathrm{~N}$ phases. The $\left(\mathrm{Fe}_{0.9} \mathrm{Co}_{0.1}\right)_{92} \mathrm{~N}_{8}$ film which prepared at substrate temperature of about $200{ }^{\circ} \mathrm{C}$ and $\mathrm{N}_{2}$ flow ratio of 1 vol. \% has maximum $4 \pi M_{s}$ of $23.9 \mathrm{kG}$. As $\mathrm{N}$ content of the film is higher than 20 at. $\%, 4 \pi M_{s}$ of the film decreases rapidly due to the formation of nonmagnetic $\zeta-\mathrm{Fe}_{2} \mathrm{~N}$ phase in the film.

\section{ACKNOWLEDGMENTS}

This work was supported by the National Science Council of ROC through Grant Nos. NSC 86-2216-E-002-029 and NSC 86-2112-M001-020.

${ }^{1}$ K. Nago, H. Sakahima, K. Ihara, and K. Osano, IEEE Trans. Magn. 28, 2943 (1992).

${ }^{2}$ B. Viala, M. K. Minor, and J. A. Bamard, IEEE Trans. Magn. 32, 3506 (1996).

${ }^{3}$ B.-II Cho, W. Win, Eui-Jung Yun, and R. M. Walser, IEEE Trans. Magn. 31, 3859 (1995).

${ }^{4}$ P. Pain, J. P. Eymery, M. F. Denanot, and J. F. Dinhut, J. Magn. Magn. Mater. 133, 493 (1994).

${ }^{5}$ D. J. Rogers, S. Wang, D. E. Laughlin, and M. H. Kryder, IEEE Trans. Magn. 28, 2418 (1992).

${ }^{6}$ J. Ching, L.-J. Chen, and C.-J. Chen, IEEE Trans. Magn. 30, 3912 (1994).

${ }^{7}$ M. Takahashi, H. Shoji, H. Takahashi, H. Nashi, and T. Wakiyama, J. Appl. Phys. 76, 6642 (1994).

${ }^{8}$ S. Takahashi, M. Kume, and K. Matsuura, IEEE Trans. Magn. 36, 1632 (1992).

${ }^{9}$ S. H. Liao, IEEE Trans. Magn. MAG-23, 2981 (1987).

${ }^{10}$ S. Nakagawa, S. Tanaka, K. Sumitsu, and M. Naoe, J. Appl. Phys. 79, 5156 (1996).

${ }^{11}$ G. Hagg, Nature (London) 122, 962 (1928).

${ }^{12}$ O. Kubaschewski, Iron-Binary Phase Diagrams (Springer, Berlin, 1982), p. 67.

${ }^{13}$ K. H. Jack, Proc. R. Soc. London, Ser. A 208, 200 (1951). 